\title{
Optimal scheduling of Park level integrated energy system considering electrothermal coupling
}

\author{
LIU Dunnan ${ }^{1}$,Gao Yuan $^{1,{ }^{*}}$,Wang Lingxiang ${ }^{1}$,Liang Jiahao ${ }^{1}$,Wang Zhenyu ${ }^{2}$,Jian Hua Zhang ${ }^{3}$ and Chun Jiang Hu ${ }^{3}$ \\ ${ }^{1}$ State Key Laboratory of Alternate Electrical Power System With Renewable Energy Sources(North China Electric Power University), \\ Changping District, Beijing 102206, China \\ ${ }^{2}$ Wuhan Efficiency Evaluation Company Limited,State Urid Electric Power Research institute, Wuhan 3007, China \\ ${ }^{3}$ State Grid Gansu Electric Power Company
}

\begin{abstract}
Considering the inherent characteristics of the park heating load, such as transmission delay, fuzzy heating comfort, etc., it can be used as a flexible load to participate in the optimal scheduling. Aiming at the minimum operation cost of the integrated energy system in the park, a collaborative optimal scheduling model of the park's integrated energy system with the participation of comprehensive demand response of electric heating load is constructed. The simulation results show that, compared with the optimization results of traditional power demand response, the application of integrated demand response of electric heating load improves the flexibility of production of cogeneration units in the park, reduces the total energy consumption cost of demand side users and the operation cost of the system on the premise of ensuring the balance of supply and demand of the system, improves the energy utilization efficiency, and realizes the environmental protection and economy of the system function.
\end{abstract}

\section{Introduction}

In recent years, the integrated energy system of cogeneration Park, represented by micro gas turbine, uses natural gas for power supply. It has the characteristics of high energy cascade utilization efficiency and flexible operation, which provides a way to further absorb renewable energy such as wind power and photovoltaic, and becomes an important direction for the development of integrated energy system in the future.

Existing studies have done some research on the demand side of integrated energy system, often using incentive signals or price elasticity based pricing to guide users to respond and participate in the optimal operation of the electricity market ${ }^{[1-2]}$. In reference [3-4], based on the real-time price minimization of comprehensive operation cost, a double-layer scheduling including microgrid layer and demand response layer is proposed. In reference [5-6], considering the wind abandonment penalty cost and demand response cost, the dispatch model of combined electric heating system was established with the minimum operation cost of power generation, which effectively improved the wind power consumption. In the aspect of system collaboration, reference [7-8] considers the multi energy complementarity of various coupling devices, and gives the corresponding optimization strategy with the minimum operation cost of the park's comprehensive energy system as the optimization objective. The paper [9-10] studied the profit strategy of CHP under the condition of multi energy complementary and coordinated operation, and discussed the economy and feasibility of different energy storage system configuration. In reference [11], aiming at minimizing the system operation cost, a bi level optimal scheduling model was established to reduce the repeated energy conversion.

Since the implementation of the above-mentioned peak load and valley load reduction, good results have been achieved in the aspects of peak load and valley load reduction. However, in the integrated energy system of the park, the schedulability of demand side heat load is seldom considered. With the deepening of electric thermal coupling, thermal demand response also has dispatching value. In this paper, the comprehensive demand response model of electric heating load is established, and it is involved in the optimal operation of comprehensive energy system in the park. The advantages of comprehensive demand response of electric heating load are proved by an example.

\section{Comprehensive load response model of energy park considering electric heating demand}

There are two modes of integrated energy system and external power grid: grid connected operation and island operation. Generally, grid connected operation has the advantage of improving the reliability of energy supply. Therefore, this paper optimizes the integrated energy

\footnotetext{
* Corresponding author:gaoyuanhd@163.com
} 
system of grid connected park. The optimization objectives include the cost of natural gas produced and consumed by gas turbine in cogeneration, the cost of natural gas consumed by gas-fired boiler, the cost of purchasing electricity from power grid The new energy abandonment cost and the operation and maintenance cost of each equipment unit.

In a scheduling cycle, the minimum total operating cost of the park's integrated energy system is taken as the objective without considering the heating demand response cost:

$$
M i n F=F^{M T}+F^{\mathrm{wp}}+F^{E X}+F^{M E}+F^{B L}(1)
$$

The comprehensive energy optimization objective function of the park consists of five parts: $F$ represents the total cost of the park's comprehensive energy system in the scheduling period; the natural gas consumption cost of micro gas turbine in the scheduling cycle is expressed by $F^{M T} ; F^{\mathrm{wp}}$ is the cost of abandoning new energy in the scheduling cycle; the power purchase cost interacting with the external large power grid in the scheduling cycle is represented by $F^{E X} ; F^{B L}$ represents the primary energy cost of natural gas consumed by gasfired boiler in the dispatching period; $F^{U / E}$ represents the operation and maintenance cost of all equipment in the system; the specific expression of each part is as follows:

$$
F^{M T}=\sum_{\mathrm{t}=1}^{T} C_{C H 4} \frac{P_{t}^{M T}}{\eta_{t}^{M T} \times L_{M T}} \cdot \Delta t
$$

Formula (2) is the fuel cost of natural gas consumed by micro gas turbine, $\mathrm{CH} 4$ is the price of natural gas, $L_{M T}$ is the low calorific value of natural gas, and $P_{t}^{M T}$ and $\eta_{t}^{M T}$ are the electric power and power generation efficiency of micro gas turbine in period $\mathrm{T}$ respectively.

$$
F^{B L}=\sum_{\mathrm{t}=1}^{T} C_{C H 4} F_{t}^{B L} \Delta t
$$

Formula (3) represents the fuel cost of natural gas consumed by gas-fired boiler, and $F_{t}^{B L}$ represents the natural gas consumption at time $\mathrm{t}$.

$$
F^{\mathrm{wp}}=\sum_{\mathrm{t}=1}^{T} X^{\mathrm{wp}}\left(\mathrm{p}_{t}^{x p_{-} \text {forecast }}-p_{t}^{x p}\right)
$$

Due to the randomness of wind power photovoltaic, the predicted output is not consistent with the actual output, so it is necessary to consider the penalty cost of wind power and photovoltaic. The sum of wind power and photovoltaic combined output is defined as new energy output. Formula (4) represents the abandonment cost of new energy, $X^{m p}$ represents the unit power penalty cost of wind abandoned new energy, $\mathrm{p}_{t}^{x p}-$ forecast represents the predicted output of new energy in period $t$, and $\mathrm{p}_{t}^{x p}$ represents the actual output of new energy in period $\mathrm{t}$.

$$
F^{E X}=\sum_{\mathrm{t}=1}^{T}\left[\frac{C_{b u y}+C_{\text {selI }}}{2} P_{t}^{e x}+\frac{C_{b u y}-C_{\text {selI }}}{2} P_{t}^{e x}\right] \Delta t
$$

In the formula, $C_{b u v}, C_{\mathrm{se} / /}$ represent the electricity purchase price, the electricity sale price $P_{t}^{e x}$ refers to the interactive power between the system and the external large power grid during $\mathrm{T}$ period, greater than zero means purchasing power from the large power grid, and negative value represents selling electricity to the external large power grid.

$$
F^{M E}=\sum_{t=1}^{T} \sum_{i=1}^{N_{m}} C_{m i}\left|P_{t}^{i}\right| \Delta t
$$

In the formula, $C_{m i}$ is the unit maintenance cost of unit I; $P_{t}^{i}$ is the output of unit I in period T;

\section{Model constraints}

(1) The power balance constraints of the park's integrated energy system;

$$
P_{t}^{\mathrm{ex}}+P_{t}^{\mathrm{wp}}+P_{t}^{M T}+P_{t}^{H S, \text { dis }}=P_{t}^{\text {load }}+P_{t}^{E B}+P_{t}^{H S, \text { in }}
$$

(2)The upper and lower limits of output of wind power, photovoltaic, micro gas turbine and gas-fired boiler are constrained;

$$
P_{\mathrm{i}}^{\min } \leq P_{\mathrm{i}}^{\mathrm{chp}} \leq P_{\mathrm{i}}^{\max }
$$

In the formula, $P_{i}^{\text {min }}, P_{\mathrm{i}}^{\min }$ are the minimum and maximum values of the output of the I th micro power source.

(3) Electric energy storage, thermal energy storage constraints;

$$
\begin{gathered}
\gamma_{E S, D} E_{\max }^{E S S} \leq E_{t}^{E S S} \leq \gamma_{E S, C} E_{\max }^{E S S} \\
\lambda_{\min } E_{\max }^{E S S} \leq E_{t}^{E S S} \leq \lambda_{\max } E_{\max }^{E S S} \\
E_{\mathrm{m} \text { in }}^{E S S} \leq E_{t}^{E S S} \leq E_{\max }^{E S S}
\end{gathered}
$$

In the formula, $E_{\min }^{E S S}, E_{\max }^{E S S}$ are the minimum and maximum capacity of energy storage; $\gamma_{E S, D}, \gamma_{E S, C}$ are the minimum maximum charge and discharge rate of energy storage; $\lambda_{\min }, \lambda_{\max }$ are the maximum and minimum state of charge of energy storage respectively

(4) The interactive power constraints between the park's integrated energy system and the external power grid tie line are as follows:

$$
P_{\mathrm{m} \text { in }}^{\text {ex }} \leq P_{t}^{e x} \leq P_{\max }^{e x}
$$

In the formula, $P_{\min }^{\mathrm{ex}}, P_{\max }^{\mathrm{ex}}$ are the minimum and maximum interactive power of tie lines.

(5) Climbing constraints of controllable units:

$$
-\mathrm{r}_{d i} \Delta t \leq P_{i, t}^{g}-P_{i, t-1}^{g} \leq \mathrm{r}_{u i} \Delta t
$$

In the formula: $\mathrm{r}_{d i}$ and $\mathrm{r}_{\mathrm{u} i}$ are the rate limits of the controllable output unit I to reduce and increase the output during the dispatching $t$ period

(6) The thermal demand responds to the constraints of heating balance;

The heat load studied in this paper is heating load. According to the delay of heat load transmission and the fuzziness of heating comfort, heat load is not like electric load, so the thermal balance does not have to meet the real-time balance, so the heat energy can be properly unbalanced between supply and demand under certain indicators, and the constraints are as follows:

$$
Q_{\mathrm{t}}^{M T-h}+Q_{\mathrm{t}}^{E B}-Q_{\mathrm{t}}^{H S, \text { in }}+Q_{\mathrm{t}}^{H S, \text { dis }}=\sigma Q_{\mathrm{t}}^{\text {load }}
$$

In the formula, $\sigma$ is the heat load adjustment coefficient.

(7) The thermal power ratio of micro gas turbine is constrained;

$$
K_{\mathrm{p} \min } \leq \frac{Q_{t}^{\mathbb{W} T-h}}{P_{t}^{\mathbb{M} T}} \leq K_{\mathrm{p} \max }
$$


In the formula, $K_{\mathrm{p} \max }, K_{\mathrm{p} \min }$ are the maximum and minimum values of thermoelectric ratio of micro gas turbine.

\section{Example simulation}

In order to verify the effectiveness of the proposed model, an integrated energy system of a park in a certain region of China is selected. Taking 24 hours a day as the dispatching time, the unit dispatching time is $0.5 \mathrm{~h}$, and all the flue gas discharged from the micro gas turbine is sent to the waste heat boiler. Figure 4.1 shows the power and heat load curve of the system and the joint forecast output curve of wind power and photovoltaic. The self elasticity coefficient of electricity price type demand response is -0.2 , and the cross elasticity coefficient is 0.03 . The purchase price of the park is 1.2 yuan / kwh; the selling price is 0.7 yuan / $\mathrm{kwh}$; the thermal resistance $\mathrm{R}$ of buildings in response to thermal demand is $18 \mathrm{oC} /$ $\mathrm{kW}$, and the optimal indoor temperature of buildings is $21^{\circ} \mathrm{C}$. The minimum is $18^{\circ} \mathrm{C}$ and the maximum is $24^{\circ} \mathrm{C}$. Table 5 shows the time of use price parameters. The parameters of each microgrid system are shown in Table 1. The parameters of the energy storage system are as follows: the electric energy storage charging and discharging rate is 0.9 , the self consumption rate is 0.001 , the minimum capacity is $30 \mathrm{MW}$, the maximum capacity is $150 \mathrm{MW}$; the heat storage charging and discharging rate is 0.9 , the self consumption rate is 0.01 , the minimum capacity is $0 \mathrm{mw}$, and the maximum capacity is $100 \mathrm{MW}$. The peak valley period is divided as follows: peak period: 11-20,1.2yuan / kwh; normal period: 710,13-14,21-22,0.8 yuan / $\mathrm{kwh}$; valley period: 236,0.4yuan / kWh.

Table 1.Operation parameters of comprehensive energy system

\begin{tabular}{cccc}
\multicolumn{4}{c}{ in the park } \\
\hline Type & $\mathrm{P}_{\min }$ & $\mathrm{P}_{\max }$ & $\mathrm{C}_{\mathrm{m}}$ \\
\hline Micro gas turbine & 150 & 500 & 0.025 \\
& & & \\
Gas fired boiler & 50 & 400 & 0.026 \\
Electric boiler & 0 & 500 & 0.0166 \\
Wind power & 0 & 100 & 0.0196 \\
photovoltaic & 0 & 100 & 0.0235 \\
power grid & - & 100 & $/$
\end{tabular}

In order to verify the advantages of the park's integrated energy system considering the comprehensive demand response of multiple electric loads, the following scenarios are set for comparison:

Mode 1: demand response is not considered

Mode 2: only the demand side response of electricity price type is considered

Mode 3: only thermal demand side response is considered

Mode 4: the comprehensive demand response of electric heating load is considered

In order to verify the superiority of the proposed model, matlab programming is used for simulation calculation, and the day ahead optimization results of the park's comprehensive energy system under different operation modes are obtained.

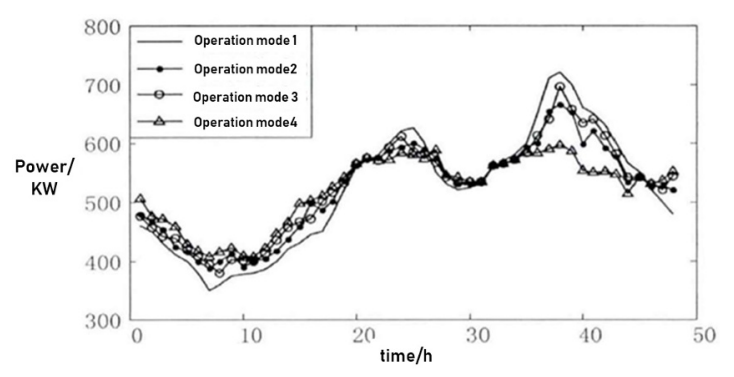

Figure 1.Optimization curve of demand side power load under different operation modes

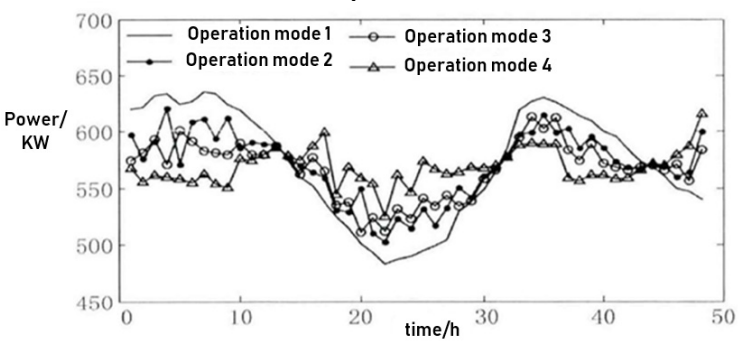

Figure 2.Optimization curve of demand side thermal load under different operation modes

It can be seen from Figure 1 and Figure 2 that compared with mode 1 without considering demand response, the electric heating load in peak period is reduced while that in valley period is increased, and the effect of mode 4 is more obvious. Therefore, considering the comprehensive demand response of electric heating load in the integrated energy management, the electric load and thermal load will be smoother, which has obvious peak shaving and valley filling effect.

Table 2.System operation cost, energy utilization efficiency and new energy abandonment in different modes

\begin{tabular}{cccc}
\hline $\begin{array}{c}\text { Operation } \\
\text { mode }\end{array}$ & $\begin{array}{c}\text { System } \\
\text { operation } \\
\text { cost }\end{array}$ & $\begin{array}{c}\text { Energy } \\
\text { utilization } \\
\text { efficiency }\end{array}$ & $\begin{array}{c}\text { New energy } \\
\text { abandonment } \\
\text { rate }\end{array}$ \\
\hline Mode 1 & 11664.5 & 81.31 & 34 \\
Mode 2 & 11443.2 & 86.35 & 27.5 \\
Mode 3 & 11421.3 & 86.86 & 19 \\
Mode 4 & 10211.8 & 89.61 & 15.5 \\
\hline
\end{tabular}

In the model calculation, it can be seen that in mode 4 operation mode, the electric output of gas turbine unit is relatively stable with small fluctuation, and the operation of gas turbine unit is stable. During the period of 2-10, when the demand response is not considered, the output of micro gas turbine fluctuates greatly, and the flexibility of the unit is low due to the influence of "determining power by heat". The flexibility of cogeneration units can be effectively improved by considering the electric heating, considering the demand response comprehensively, the influence of power load on the price type demand response, and the influence of heating transmission delay and heating comfort fuzziness on the thermal load. When the demand response is not considered, the combined output level of new energy is higher between 0 and 15, while the heating is in the peak period. The cogeneration unit is affected by "determining power by heat", and its power output level is high, and the output space of new energy is compressed, which leads to the abandonment of new energy. The introduction of demand response in the demand side can solve the problems of cogeneration units and break the constraint of "determining electricity 
by heat". Mode 4 has a higher consumption of new energy.

It can be seen from table 2 that when demand response is not implemented, the operating cost of the system is 11664.5 yuan, and the operating cost of the integrated electric heating demand response system is 10211.8 yuan, the cost is reduced and the new energy consumption rate is improved. The primary energy utilization efficiency of comprehensive demand response of electric heating load increased from $81 \%$ to $89.56 \%$.

\section{Conclusion}

In the integrated energy system of the park, the schedulability of demand side heat load is seldom considered. With the deepening of electric thermal coupling, thermal demand response also has dispatching value. In this paper, the comprehensive demand response model of electric heating load is established, and it is involved in the optimal operation of comprehensive energy system in the park. The advantages of comprehensive demand response of electric heating load are proved by an example. In the optimization of integrated energy system in the park, considering the comprehensive demand response of electric heating can realize the complementary advantages between them, improve the energy utilization efficiency, coordinate the optimization of power supply in the network, and reduce the energy consumption cost of the integrated energy system.

\section{References}

1. Shariatkhah M-H, Haghifam M-R, Mohesn P$\mathrm{M}$, et al . Modelling the reliability of multicarrier energy systems considering dynamic behavior of thermal loads[J] . Energy Build, 2015(103): 375-383 .

2. Zare M, Niknam T, Azizipanah-Abarghooee R, et aLNew stochastic bi-objective optimal cost and chance of operation management[J].IEEE Transactions on Industrial Informatics .2016,12(6):2031-2040

3. Zhang Cuo,Xu Yan,Dong Zhaoyang.et a1.Robust coordination of distributed generation and pricebased demand response in microgrids[J]. IEEE Transactions on Smart Grid .2017,PP(99):1-1.

4. Chen Ran, Yang Chao, Shen Bing, et al. Demand response optimization strategy based on Microgrid [J]. Power system protection and control, 2018,46 (11): 124-130

5. Mi Yang, Li Zhanqiang, Wu Yanwei, et al. Two level optimal dispatching of grid connected microgrid based on two-level demand response [J]. Power grid technology, 2018,42 (06): 1899-1906

6. Zhang Yining, he Yubin, Yan Mingyu, et al. Power system automation, 2018,42 (20): 1-10

7. Jiang X S, Jiang Z X, Li Y Z, et a1.Modelling and operation optimization of an integrated energy based direct district water-heating system[J].Energy, 2014,64(1): 375-388.

8. Jiang $\mathrm{Z} \mathrm{X}$, Jiang X S, Wu Q H, et a1.Modelling and optimal of a small-scale integrated energy based district heating and cooling system[刀 Energy, 2014,73(73):399-415

9. Xiong Wen, Liu Yuquan, Su wanhuang, et al. Optimal allocation of multiple energy storage in regional integrated energy system considering multi energy complementary [J]. Power automation equipment, 2019, 39 (01) 118-126

10. Zhang Shixiang, LV SHUAIKANG. Evaluation method of integrated energy system for park microgrid [J]. Power grid technology, 2018,42 (08): 2431-2439

11. Feng Qiming, Liu Jichun, Yang Yangfang, et al. Economic operation of integrated energy system considering energy re conversion $[[\mathrm{J}]$. Electric power construction, 2018,39 (12): 47-5 